\title{
Evaluation of the EFFiciency ANd RANKING OF PRimary SCHOOLS IN CANTON SARAJEVO USING DEA
}

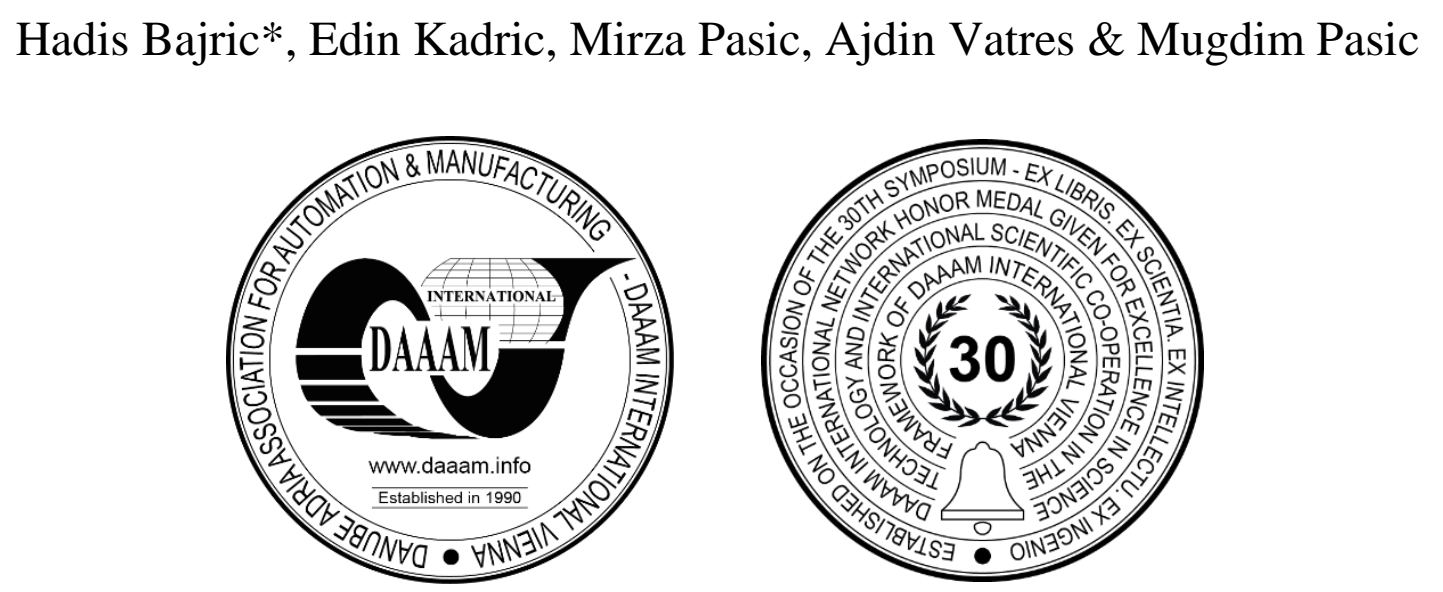

This Publication has to be referred as: Bajric, H[adis]; Kadric, E[din]; Pasic, M[irza]; Vatres, A[jdin] \& Pasic, M[ugdim] (2019). Evaluation of the Efficiency and Ranking of Primary Schools in Canton Sarajevo Using DEA, Proceedings of the 30th DAAAM International Symposium, pp.0115-0122, B. Katalinic (Ed.), Published by DAAAM International, ISBN 978-3-902734-22-8, ISSN 1726-9679, Vienna, Austria DOI: $10.2507 / 30$ th.daaam.proceedings.015

\begin{abstract}
The aim of this paper is to analyse efficiency of primary schools in Canton Sarajevo in Bosnia and Herzegovina, to identify efficient and inefficient schools, to indicate how much efficiency of inefficient schools can be improved and to rank the schools according to their efficiency. The data were obtained from the Ministry of Education, Science and Youth of Canton Sarajevo for the period from 2016 to 2017. Data envelopment analysis (DEA) method was used to evaluate the efficiency of primary schools. A comparison of the efficiency of primary schools and a ranking according to the efficiency of work in 2016 and 2017 was made as well as for the two-year period (2016-2017). Projections of the increase in the number of pupils who successfully completed the school year, as well as the increase in the average score in the native language, the first foreign language and mathematics are made, given that all schools work efficiently.
\end{abstract}

Keywords: DEA method; Efficiency assessment; Ranking of primary schools; Output-oriented CCR model

\section{Introduction}

In [1], the efficiency of 465 primary schools in Rio de Janeiro is tested, using DEA analysis. Analysis is done using the model defined in [2]. The sample of 813 primary schools is selected, but 465 schools could provide all data needed for analysis. The aim of the paper is to find variables that affect efficiency and find ways that can help managers improve efficiency. The analysis consists of two phases. In the first phase, the efficiency of schools was tested using the DEA method. Inputs are taken: number of computers, number of employees, number of rooms and number of teachers, and outputs are: average score obtained from Prova Brazil, average pass rate and number of pupils at school. In the second phase, "bootstrapped truncated regression" was used, which was based on methodology presented in [2] and environmental variables that are significant for efficiency were found.

As a result of the first phase from 465 schools, 30 had technical efficiency, 65 were efficient, 30 had scale efficiency, 430 were classified as Decreasing return to scale (DRS) and 5 as Increasing return to scale (IRS). As a result of the second phase, more efficient schools with less students were established. Schools with more children involved in preschool have reduced efficiency. In the second phase, variables that are significant for efficiency are identified. It was concluded that the socioeconomic level of students does not affect the level of efficiency. Variables that affect less efficiency include 
longer school days, student discipline problems, frequent teacher absences, and lack of solidarity or community clean-up programs.

The effectiveness of schools is also examined in [3]. The efficiency of schools in Shanghai China for its 17 districts is tested using the DEA method (model). Primary and secondary education is analysed for students aged between 7 and 15 years for 17 districts in Shag Hai. Efficiency analysis is performed using the DEA method. The 6 main indicators of the education budget executive evaluation, for the period 2008-2012, for each district are calculated and the mean values for each indicator are calculated. The main indicators are: total budget per capita, equipment per capita, student/teacher ratio, quota per class, quota per school, student density per $\mathrm{km}^{2}$. After the use of the DEA, it is concluded that 5 districts had $100 \%$ efficiency, two of which were urban districts and the others were suburban districts. Almost all of the districts had greater efficiency than the mean values. It turned out that the effectiveness of education is not affected by whether the educational institution (school) is rich or not. The results of the efficiency analysis can serve as a good source of information on the basis of which the government can plan the allocation of education resources for the future.

An analysis of the efficiency of education in Abu Dhabi in secondary schools using the DEA method is done in [4]. This analysis is important because Abu Dhabi is trying to unify all schools into a new school model (NSM) within 5 years, starting in 2009. The data are used for academic year 2009-2010 for public secondary schools, located in urban areas, operating for at least 5 years. These requirements are fulfilled by 22 schools. Inputs are average student cost per school, average teacher cost per school, classroom utilization, teacher-student ratio in school and the teacher load. The average score of the exams (12th grade average exit exam results called Thanawiah), CEPA (Common Educational Proficiency Assessment) average scores and EMSA (English, Math, Science and Arabic) average scores are included as outputs. For defined input and output variables more DEA models have been developed by performing several different combinations of these variables in order to find the best combination. Sensitivity analysis shown that input variables that have a major impact on the efficiency of the school are: costs per student, costs per teacher and maximum class size. Output variables that have a major impact on school efficiency are student tests. It is determined through a variance analysis that the location and type of school have a significant impact on the efficiency of the school. The results of the regression showed that for the efficiency of the school there are significant variables of the costs per student and the costs per teacher.

In the paper [5], the efficiency of the university is assessed using the DEA method. Relative teaching efficiency and relative research efficiency are evaluated. As the resources for public universities are limited and student enrollment is getting higher, the authors felt that it was necessary to examine the efficiency of universities in order to properly allocate resources and improve the quality of universities. Since there is no standard instruction to take variables as inputs or outputs, authors used number of researchers, average qualification of the researcher, number of students, university expanditures and subsidies for research as inputs for analysing research efficiency. Number of graduates from research, number of publications, number of awards and number of intellectual properties are taken as outputs. For examination of teaching efficiency number of academic staff, number of taught course students, average qualification of students and university expanditures are taken as inputs. As outputs, number of graduates, average graduates' results, graduation rate and the graduates' employment rate are taken. An application model has been developed for a hypothetical example of 30 universities. The model has proved very powerful in distinguishing efficient from inefficient universities. This analysis allows professors and university management to identify shortcomings at their universities and take appropriate measures to increase efficiency.

The effectiveness of public schools in Oklahoma is examined in [6]. Using the DEA method, the efficiency of schools is tested, while Tobit regression tested possible causes of poor efficiency. In the United States, there is a noticeable increase in costs for public schools, while the quality of schools has little or no progress. The data required for this research were provided by the Oklahoma Department of Education, the Office of Accountability for Academic Years 1996-1997, 19971998, 1998-1999. These are some socioeconomic data of students: students who have subsidized lunch, the level of parenting, family income, etc. For outputs, student succses data are taken. Iowa Test of Basic Skills (ITBS) and Criterion Reference Test (CRT) are taken as the most relevant student testing. ITBS tests are used for students which are third and seventh grade, while CRT is used for grades 5, 8, and 11. Efficiency measurements are carried out for 354 schools with complete information. The test is carried out through MODEL I and MODEL II. In both models, the first DEA method is used, followed by Tibot regression, and the difference is that different combinations of input parameters are used. By comparing the results of MODEL I and MODEL II, conclusions are drawn. Both models show that the variables on which school cannot be influenced: percentage of minority students, percentage of students in special education, percentage of students eligible for reduced or free lunch, decreases efficiency. Teachers' salary, teachers' experience, teachers with a high degree of education and school size are variables that school district can control and they are not significant for the efficiency of schools. Student/teacher ratio is increasing efficiency. It is concluded that characteristic of students and the family environment are major factors that influence school performance in Oklahoma.

The paper [7] presents examining the efficiency of public primary schools in Andorra. 25 primary schools with different educational systems are analysed for a period of 5 years. The DEA method was used in order to find variables that affect efficiency in schools. After that two non-parametric tests are carried out: the median test and the Kruskal-Wallis test in order to compare the effectiveness of education systems and to show which one is better. Data on the total number of students per year are obtained from the National Statistic Service of the Government of Andorra. Other data are obtained from the Ministry of Education of the Government of Andorra, where it is necessary to sign an agreement on the anonymity of the data. Regarding input and output data, two general inputs have been used: financial and human resources. Since in Andorra there is no uniform test for all educational systems, the output is taken by the number of 
students who passed the next year successfully. The number of students is taken as the second output. After the DEA analysis with the use of bootstrap techniques, it is concluded that reducing school efficiency trough years is a consequence of the decrease in the number of inhabitants of Andorra and the number of pupils in primary schools. It is concluded that that education systems differ significantly. It is noted that the educational system $\mathrm{C}$ has a higher median efficiency value and a higher mean efficiency rank value, while system B has lower values. There are beneficial effects of decentralization (autonomy in school management), which is characteristic of system $\mathrm{C}$ and stability of staff during the time, which is not a feature of system B, on the effectiveness of schools. The paper does not discuss environmental variables and their impact on the efficiency of schools, so this is proposed for future research.

In most European countries, monetary expenses for the secondary education system are higher than for other educational levels, so the examination of the effectiveness of secondary education is therefore very important [8]. The paper is used to measure relative efficiency in selected EU and OECD (Organisation for Economic Co-operation and Development) countries, including Slovenia and Croatia. DEA method is used to measure the efficiency. Testing is done through 4 MODELS, combining different types of inputs and outputs. In this paper, the input variables are taken: costs per student in secondary schools ( $\%$ of GDP per capita), teacher pupil ratio, secondary, school enrolment, secondary (\% gross). For the output, school enrolment, secondary (\% gross), PISA (Programme for International Student Assessment) average (2006), teacher-pupil ratio, secondary, school enrolment, tertiary (\% gross) were taken. As a result of the analysis, for each model, a list of countries is formed according to technical efficiency. The results of the survey show that in the field of secondary education, in the most countries, expenditures are higher than in others levels of education. Great diversity in the efficiency of secondary education among countries is observed. Low efficiency is present in new EU member states, including Croatia and in OECD members. The results of the analysis show that Slovenia and Croatia have a relatively low level of efficiency in secondary education, because they allocated a lot of public money for secondary education without big results. Estonia, Poland, Slovakia and Latvia have less education spending, but better PISA 2009 results than Croatia. It is recommended that the secondary education system in both Croatia and Slovenia should be modernized.

The aim of [9] is to determine the relative cost effectiveness of the education set aside in new EU member states (plus Croatia) and OECD countries. In this paper, relative efficiency is measured, with the aim of reducing the cost of education without compromising quality. DEA method is used for analysis. In the DEA method, the choice of input and output variables is very important. Inputs are expanditures per student, tertiary (\% of GDP per capita) or total expanditures on education (in \% of GDP). Outputs are school enrolment, tertiary (\% gross), teacher/pupil ratio, primary completion rate, total ( $\%$ of relevant age group), unemployment with tertiary education ( $\%$ of total unemployment), labor force with tertiary education (\% of total) and PISA 2006 average score. Analysis included 37 countries. The method has been implemented four times, each time with a different combination of certain inputs and outputs. The results of the DEA methods show a difference in the level of technical efficiency between EU (European Union) countries, including EE (Eastern European) countries and OECD countries. Japan, Korea and Finland have the highest efficiency of the education system. If only EE countries are considered, Hungary, Estonia and Slovenia have a good level of efficiency in all three levels of education. The results show that all EE countries have good efficiency in terms of tertiary education. The analysis shows that most EE countries can significantly reduce costs while maintaining the same quality of education. Further research recommends improving the quality of data and examining the impact of environmental variables on the effectiveness of the education system.

In this paper [10], DEA method is used to compare efficiency of 19 technological universities in Poland. The paper presents a detailed analysis of potential inputs, outputs and environmental variables. 15 variables are taken into consideration (5 inputs, 8 outputs and 2 environmental variables). Input variables are government subsidies, number of academic staff, number of other employees, number of licenses for $\mathrm{PhD}$ degree and number of licenses for more doctoral degrees. Output variables are the weighted average number of students, the percentage of PhD students, the percentage of students in exchange, the percentage of international students, the percentage of students with scholarships from universities, the percentage of students with scholarships from the government, the preferences of employees to include alumni and the parametric assessment of the scientific achievements of the faculty. Environmental variables are the population of the city where the university is located and the percentage of students requiring financial assistance. First, a series of correlations were made between input, output and environmental variables. The research has shown that there is great diversity of Polish universities as far as efficiency is concerned. Two universities are efficient and they can serve as an example to improve the efficiency of other universities. The authors believe that this comparative efficiency analysis is a good way to improve the quality of inefficient universities and to improve overall efficiency through better allocation and spending of public funds.

\section{Methodology}

The applied methodology for evaluating the effectiveness of primary schools in Canton Sarajevo (CS) is adopted after reviewing the literature and published papers that were available in international publications and scientific bases. For the purpose of evaluating the efficiency of primary schools in CS, the original data collection was done directly by the Ministry of Education of CS, and it can be said that it had reliable and high-quality information relating to the period from 2015 to 2017.

For the purposes of analysing work efficiency and ranking of primary schools in CS, the CCR model developed by Charnes, Cooper, and Rhodes is selected [11]. This model assumes a constant return on volume (CRS). For details on the 
model itself and its mathematical formulation, see [11]. The CCR model is probably the most famous and commonly used DEA model.

The output-oriented CCR-CRS model, in the case of primary school efficiency analysis, provides information on how much primary school can increase its outputs (number of students who successfully completed the school year, average points achieved in Bosnian / Croatian / Serbian (B / C / S) language and literature, mathematics and in the first foreign language at the secondary school certificate testing.) while maintaining the same level of input (total school costs). For the purposes of analysis, and from the perspective of input variables that were of interest for evaluating the efficiency and ranking of primary schools in CS, the following data were available: number of staff employed at school, number of non-teaching staff employed at school, number of hours spent teaching through external associates, total school costs in BAM (salaries, material costs,...), property value without building (equipment, inventory,...) variables, the number of staff employed at school and the number of non-teaching staff employed at school are statistically strongly correlated with the variable total school costs in BAM (salaries, material costs,...), 0.83 and 0.76 , respectively. Due to the high correlation of these variables with the variable total school costs in BAM and to avoid the occurrence of multicollinearity, these two variables were not used in the analysis.

Variable The number of hours spent teaching through external assistants was recorded in only one school in a set of 57 schools and was not considered statistically significant.

Different schools have used different approaches to assess the value of property without a building (equipment, inventory...), which resulted in large variations in this data. In addition to applying different approaches to assessing these values, large variations are also expected because there is considerable heterogeneity in the age and equipment of the schools themselves. Due to the above remarks, this variable is not used in the subject analysis. Variable The total cost of a school in BAM (salaries, material costs,...) is considered to be the most important input variable, since it has a direct impact on the output variables, ie the overall success of the school, ie its efficiency. For the purposes of the analysis and from the perspective of the output variables that were of interest for evaluating the efficiency and ranking of primary schools in CS, the following data were available: Total number of students in all grades (grades 1 through 9); number of students who successfully completed the school year; average points achieved in B / C / $\mathrm{S}$ language and literature at the secondary school certificate testing; average points achieved in mathematics at the secondary school certificate testing; average points achieved in the first foreign language at the secondary school certificate testing; total number of first, second and third places won at cantonal, federal, state, olympics, European and world competitions.

The following variables were adopted as relevant for the analysis: number of students who successfully completed the school year, average points achieved in B / C / S language and literature, mathematics and in the first foreign language at the secondary school certificate testing. These variables represent the overall success of a student and they cover all students of any school.

Variables related to student success in domestic and international competitions were not used in the analysis, as they are the result of the excellence of a very small number of students who can be considered non-standard data from a statistical point of view. Non-standard data very often lead to wrong conclusions, which is why such data are excluded from analyses.

In paper [12] 10 different models were made that evaluate relative efficiency of primary schools in CS. The models developed in this paper have tested different combinations of the previously mentioned inputs and outputs. After analysing various rankings achieved by Decision Making Units (DMU) for different models, it was concluded that the best model was the output oriented CCR-CRS which used one input variable (total school costs in BAM) and four output variables (number of students who successfully completed the school year; average points achieved in B / C / S language and literature at the secondary school certificate testing; average points achieved in mathematics at the secondary school certificate testing; average points achieved in the first foreign language at the secondary school certificate testing).

The DEA method by itself does not provide guidelines for the selection of input and output variables in the model. However, the results of the DEA method analysis depend on the number of variables used in the model, relative to the number of DMUs. The evaluative power of the DEA method depends on the number of DMUs and the number of variables. Decreasing the number of DMUs and / or increasing the number of variables in the DEA model leads to an increase in the efficiency of the DMUs, thus reducing the evaluative power of the DEA method [13]. Based on the literature [14], [15], [16], [17] and [18] several different criteria for the formation of a valid DEA model can be distinguished. Our model furfilled all of the determined cirteria from the literature.

\section{Result analysis}

The average efficiency (efficiency refers to the relative efficiency calculated by the DEA method for the selected group) of all primary schools is 0.6935 or $69.35 \%$ of their capacity, while the average efficiency of inefficient primary schools is 0.6765 or $67.65 \%$ of their capacity. From Table 1 it can be seen that out of 57 primary schools 3 primary schools are efficient and they form the envelope of efficiency. The remaining 54 primary schools can improve their efficiency by increasing the average score in the native language, the first foreign language and mathematics as output, without increasing the total cost as input. It should be emphasized once again that the DEA is evaluating relative efficiencies and that absolute efficiency or theoretically maximum efficiency of primary schools is not discussed here. 
In order to equalize the potential disparities in the input and output variables through the non-homogeneous values of the total costs of operating primary schools and the number of students who successfully completed the school year, efficiency analysis was conducted for a period of two years (2016-2017) and this analysis is most relevant for the evaluation of work efficiency and ranking of primary schools in this paper. In addition to this analysis, analyses were also made for each year (Table 1). Table 2 summarizes the efficiency statistics for the analyses performed.

\begin{tabular}{|c|c|c|c|c|c|c|}
\hline \multirow[t]{2}{*}{ Primary school (PS) } & \multicolumn{3}{|l|}{ Efficiency } & \multicolumn{3}{|l|}{ Rank } \\
\hline & 2016-2017 & 2016 & 2017 & 2016-2017 & 2016 & 2017 \\
\hline PS Hadžići & 1 & 1 & 0,77245 & 1 & 1 & 21 \\
\hline PS Hasan Kikić & 1 & 1 & 1 & 1 & 1 & 1 \\
\hline PS Musa Ćazim Ćatić & 1 & 0,67875 & 1 & 1 & 6 & 1 \\
\hline PS Saburina & 0,9321 & 0,59482 & 0,97374 & 4 & 11 & 3 \\
\hline PS Ćamil Sijarić & 0,90852 & 0,64881 & 0,92067 & 5 & 8 & 4 \\
\hline PS Šejh Muhamed ef. Hadžijamaković & 0,90783 & 0,68629 & 0,84586 & 6 & 5 & 9 \\
\hline PS Zahid Baručija & 0,89989 & 0,70586 & 0,88754 & 7 & 4 & 7 \\
\hline PS Hasan Kaimija & 0,82633 & 0,7388 & 0,91613 & 8 & 3 & 5 \\
\hline PS Zaim Kolar & 0,81367 & 0,62451 & 0,80522 & 9 & 9 & 16 \\
\hline Šesta PS & 0,793 & 0,48908 & 0,90134 & 10 & 18 & 6 \\
\hline PS Mirsad Prnjavorac & 0,76249 & 0,38111 & 0,88375 & 11 & 41 & 8 \\
\hline PS Zajko Delić & 0,74862 & 0,54649 & 0,73113 & 12 & 12 & 26 \\
\hline PS Pofalići & 0,7376 & 0,41171 & 0,81327 & 13 & 34 & 14 \\
\hline Osma PS & 0,73016 & 0,65613 & 0,70168 & 14 & 7 & 34 \\
\hline PS Vladislav Skarić & 0,72616 & 0,46437 & 0,78627 & 15 & 24 & 18 \\
\hline PS Skender Kulenović & 0,72569 & 0,35829 & 0,83271 & 16 & 48 & 10 \\
\hline PS Mehmedalija Mak Dizdar & 0,72502 & 0,54069 & 0,77408 & 17 & 14 & 19 \\
\hline KŠC & 0,72334 & 0,41402 & 0,82011 & 18 & 31 & 11 \\
\hline PS Nafija Sarajlić & 0,72004 & 0,39446 & 0,77329 & 19 & 37 & 20 \\
\hline PS Umihana Čuvidina & 0,7174 & 0,38435 & 0,81937 & 20 & 40 & 12 \\
\hline Treća PS & 0,71498 & 0,54408 & 0,73101 & 21 & 13 & 27 \\
\hline PS Avdo Smailović & 0,7122 & 0,3692 & 0,81177 & 22 & 44 & 15 \\
\hline PS Sokolje & 0,71084 & 0,46612 & 0,7888 & 23 & 23 & 17 \\
\hline PS Aleksa Šantić & 0,71025 & 0,35092 & 0,81422 & 24 & 52 & 13 \\
\hline PS Izet Šabić & 0,69913 & 0,47457 & 0,71273 & 25 & 20 & 30 \\
\hline PS Mustafa Busuladžić & 0,68581 & 0,48309 & 0,72335 & 26 & 19 & 28 \\
\hline PS Fatima Gunjić & 0,68295 & 0,43017 & 0,74687 & 27 & 29 & 23 \\
\hline PS Velešićki heroji & 0,67356 & 0,46627 & 0,7346 & 28 & 22 & 25 \\
\hline Četvrta PS Hrasnica & 0,67068 & \begin{tabular}{|l|}
0,59744 \\
\end{tabular} & 0,71055 & 29 & 10 & 31 \\
\hline PS Mehmed-beg Kapetanovic Ljubušak & 0,66947 & 0,472 & 0,70244 & 30 & 21 & 33 \\
\hline PS Osman Nuri Hadžić & 0,66452 & 0,39937 & 0,75585 & 31 & 36 & 22 \\
\hline PS Mula Mustafa Bašeskija & 0,66422 & 0,49862 & 0,67817 & 32 & 16 & 40 \\
\hline Deseta PS & 0,66278 & 0,41348 & 0,73994 & 33 & 32 & 24 \\
\hline PS Meša Selimović & 0,65163 & 0,41187 & 0,69261 & 34 & 33 & 36 \\
\hline PS Hašim Spahić & 0,64488 & 0,37509 & 0,71885 & 35 & 42 & 29 \\
\hline PS Hrasno & 0,62893 & 0,34192 & 0,68028 & 36 & 53 & 39 \\
\hline Peta PS & 0,62225 & 0,3894 & 0,68931 & 37 & 39 & 38 \\
\hline PS Hamdija Kreševljaković & 0,61916 & 0,44776 & 0,64721 & 38 & 26 & 45 \\
\hline Druga PS & 0,61811 & 0,35143 & 0,69201 & 39 & 50 & 37 \\
\hline Prva PS & 0,61777 & 0,37243 & 0,6432 & 40 & 43 & 46 \\
\hline PS Safvet-beg Bašagić & 0,61691 & 0,43516 & 0,63825 & 41 & 28 & 49 \\
\hline
\end{tabular}




\begin{tabular}{|l|l|l|l|l|l|l|}
\hline Sedma PS & 0,61193 & 0,36346 & 0,70742 & 42 & 45 & 32 \\
\hline PS Grbavica 1 & 0,61121 & 0,33887 & 0,65915 & 43 & 54 & 41 \\
\hline PS Džemaludin Čaušević & 0,60465 & 0,45447 & 0,63432 & 44 & 25 & 50 \\
\hline PS Vrhbosna & 0,59613 & 0,41716 & 0,6478 & 45 & 30 & 44 \\
\hline PS Ćengić Vila & 0,59271 & 0,35118 & 0,65021 & 46 & 51 & 43 \\
\hline PS Podlugovi & 0,59186 & 0,35417 & 0,64082 & 47 & 49 & 47 \\
\hline PS Grbavica 2 & 0,59174 & 0,36346 & 0,62123 & 48 & 45 & 51 \\
\hline PS Kovačići & 0,58822 & 0,4465 & 0,59883 & 49 & 27 & 52 \\
\hline PS Srednje & 0,58695 & 0,52061 & 0,58871 & 50 & 15 & 54 \\
\hline PS Deveti maj & 0,58336 & 0,32409 & 0,64044 & 51 & 55 & 48 \\
\hline PS Hilmi ef. Šarić & 0,57737 & 0,3901 & 0,65677 & 52 & 38 & 42 \\
\hline PS Porodice ef. Ramić & 0,57467 & 0,49769 & 0,5736 & 53 & 17 & 55 \\
\hline PS Stari Ilijaš & 0,57365 & 0,40628 & 0,59731 & 54 & 35 & 53 \\
\hline PS Malta & 0,53941 & 0,36036 & 0,53496 & 55 & 47 & 56 \\
\hline PS Šesti maj & 0,51054 & 0,23363 & 0,69805 & 56 & 57 & 35 \\
\hline PS Edhem Mulabdić & 0,45865 & 0,26743 & 0,48683 & 57 & 56 & 57 \\
\hline
\end{tabular}

Table 1. The efficiency of primary schools in CS for 2016 and 2017 and the period 2016-2017

\begin{tabular}{|l|l|l|l|}
\hline \multirow{2}{*}{ Statistical indicator } & \multicolumn{2}{|l|}{ Efficiency } \\
\cline { 2 - 4 } & $\mathbf{2 0 1 6 - 2 0 1 7}$ & $\mathbf{2 0 1 6}$ & $\mathbf{2 0 1 7}$ \\
\hline Average & 0,6935 & 0,4719 & 0,7359 \\
\hline Max & 1 & 1 & 1 \\
\hline Min & 0,45865 & 0,23363 & 0,48683 \\
\hline St Dev & 0,1213 & 0,1506 & 0,1122 \\
\hline Number of efficient primary schools & 3 & 2 & 2 \\
\hline Number of inefficient primary schools & 54 & 55 & 55 \\
\hline
\end{tabular}

Table 2. Summary statistics on the efficiency of primary schools in CS

The average efficiency of primary schools in 2016 was $47.19 \%$, in 2017 it was $73.59 \%$, while in 2016-2017 it was $69.35 \%$. In both years 55 primary schools were recorded as inefficient. Only two schools operated at 100\% efficiency. In 2016, these were primary schools Hadžići and Hasan Kikić, while in 2017 these were primary schools Hasan Kikić and Musa Ćazim Ćatić. According to the most relevant analysis in this paper, which is the analysis for the period 2016-2017, 54 primary schools were inefficient, while 3 were $100 \%$ efficient. The $100 \%$ efficient primary schools are Hadžići, Hasan Kikić and Musa Ćazim Ćatić. The three most inefficient primary schools were Malta, Šesti maj and Edhem Mulabdić.

One advantage of the DEA method is the ability to quantify performance improvement opportunities for all inefficient primary schools according to each variable that have been used in the model. Using this DEA ability, it was established that primary schools in CS, in case they do everything efficiently and while maintaining the existing level of total costs and number of employees, have the potential to:

- increase the number of students who have successfully completed the school year by $106 \%$,

- increase the number of points earned in B / C / S languages and literature by $188 \%$,

- increase the number of points in mathematics by $239 \%$, and

- increase the number of points earned in the first foreign language by $189 \%$.

Based on the analysis, it can be concluded that the current level of employees in primary schools in CS, teaching and nonteaching staff, as well as the costs of operating primary schools is sufficient to significantly improve the efficiency of school work, or to significantly improve the overall success of students of primary schools.

\section{Conclusion}

The DEA method is used to evaluate work efficiency and ranking of primary schools in Sarajevo Canton, with a focus on maximizing output, the average number of students who successfully completed the school year and the average of marks obtained in their native and first foreign languages, and mathematics, using existing resources. Data quality, number and selection of input and output variables used in DEA analysis, selection of DEA models, and other segments of 
methodology applied in this paper were adopted after reviewing the literature and published papers that were available in international publications and scientific bases.

The paper shows that, according to the aforementioned sources, the applied methodology meets even the most demanding criteria. According to the analysis of the efficiency of primary schools in CS, which related to their results in the period 2016-2017, a total of 3 effective primary schools were identified, while the remaining 54 schools are inefficient. It should be emphasized that the DEA method evaluates the relative efficiency (efficiency compared to the other schools in the considered set), and does not talk about the absolute efficiency or theoretically maximum efficiency that the schools could have achieved. This is considered to be the biggest drawback, but also the biggest advantage of the DEA method.

The disadvantage is that it is not possible to discover how much more potential has been left untapped to the theoretical maximum in inefficient as well as in schools that have been declared effective, and the advantage is that tangible evidence is obtained against inefficient schools that they can improve their efficiency at least to the extent that are achieved by schools that were declared effective because they all have the same prerequisites.

The relative efficiency assessment obtained by the DEA method, provided that the efficiency assessment of the DEA method is carried out annually, creates a competitive atmosphere among schools, which allows it to approach the theoretical maximum. For example, a school that is declared effective one year if it works with the same efficiency next year does not have to be declared effective if, in that next year, another school achieved better results than the one observed.

Based on the analysis done, it can be concluded that there is a significant difference in the efficiency of primary schools in CS. The lowest efficiency at the level of all primary schools was recorded in 2016 and amounted to 47.19\%, while the highest was in 2017 and amounted to $73.59 \%$. Both years saw an equal number of inefficient primary schools, 55 each. According to the most relevant analysis in this survey, which is the analysis for the period 2016-2017, there were 54 primary schools ineffective, while 3 schools operated at $100 \%$ efficiency. Primary schools that had $100 \%$ efficiency were Hadžići primary school, Hasan Kikić primary school and Musa Ćazim Ćatić primary school. The worst ranked schools are the Malta primary school with a 53.94\% efficiency, the Šesti maj primary school with 51.05\% efficiency, and the Edhem Mulabdić primary school with the lowest $45.87 \%$ labor efficiency.

These three efficient schools can be used as a model on which to base the improvement for the remaining schools. If all schools were to do everything effciently while retaining the same level of total costs and number of employees they could increase the number of students who have successfully completed the school year by $106 \%$, points earned in B / C / S languages and literature by $188 \%$, points in mathematics by $239 \%$ and points earned in the first foreign language by $189 \%$. Current inputs are large enough to significantly improve the overall success of students of primary schools.

\section{References}

[1] Simar, L.; Wilson, P. W. (2017): Estimation and inference in two-stage, semi-parametric models of production processes, Journal of Economics, Vol. 136, No. 1, 2017, pp. 31-64

[2] Lauro, A.; Figueiredo, O.; Wanke, P. (2016): Efficiency of municipial schools in Rio de Janeiro: Evidence from two-stage DEA, Journal of Economics and Economic Education Research, Vol. 17, No. 3, 2016 , pp. $140-166$

[3] Yuan, Y.; Shan, M. (2016): The educational efficiency evaluation framework: By using DEA model and CA method, International Journal of Information and Education Technology, Vol. 6, No. 12, December 2016, pp. 923-926

[4] Badri, M. A.; El Mourad, T. (2012): Determinants of school efficiencies in Abu Dhabi using DEA, International Conference of Management and Education Innovation, vol. 37, 2012, pp. 314-318

[5] Kuah, C. T.; Wong, K. Y. (2011): Efficiency assessment of universities through data envelopment analysis, Procedia Computer Science, ISSN 1877-0509, Vol. 3, 2011, pp. 499-506

[6] Rassouli-Currier, S. (2007): Assessing the efficiency of Oklahoma public schools: A data envelopment analysis, Southwestern economic: Review, pp. 131-144

[7] Casalprim, M.; Rialp, J.; Prior, D.; Sabrià, B. (2013): An assessment of schools' efficiency of different educational systems, Mediterranean Journal of Science, ISSN 2039-9340, Vol. 4, No. 11, October 2013, pp. 1-16

[8] Aristovnik, A.; Obadić, A. (2014): Measuring relative efficiency of secondary education in selected EU and OECD countries: the case of Slovenia and Croatia, Technological and Economic Development of Economy, Vol. 20, No. 3, August 2014, pp. 419-433

[9] Aristovnik, A (2013): Relative efficiency of education expanditures in Eastern Europe: A non-parametric approach, Journal of Knowledge Management, Economics and Information Technology, Vol 3., No. 3, June 2013, pp. 1-13

[10] Nazarko, J.; Šaparauskas, J. (2014): Application of DEA method in efficiency evaluation of public higher education institutions, Tecnhological and Economic Development of Economy, ISSN 2029-4913, Vol. 20, No. 1, 2014, pp. 25-44 
[11] Charnes, A.; Cooper, W.W.; Rhodes, E. (1978): Measuring the efficiency of decision making units, European Journal of Operational Research, Vol. 2, No. 6, November 1978, pp. 429-444.

[12] Bajric, H.; Kadric, E.; Pasic, M.; Pasic, M.; Vatres, A. (2019): Development DEA models for assessment of efficiency of primary schools in Sarajevo Canton, 11. Naucno-strucni skup sa medunarodnim ucescem “QUALITY 2019”, ISSN 1512-9268, June 14-16, 2019, Neum, Bosnia and Herzegovina, pp. 435-440

[13] Khezrimotlagh, D. (2015). How to deal with numbers of decision making units and variables in data envelopment analysis, Proceedings of 13th International Conference on Data Envelopment Analysis, August 24-27, 2015, Braunschweig, Germany.

[14] Dyson, R.; Allen, R.; Camanho, A.; Podinovski, V.; Sarrico, C.; Shale, E. (2001). Pitfalls and protocols in DEA, European Journal of Operational Research, Vol. 132, No. 2, 2001, pp. 245-259.

[15] Amirteimoori, A.; Despotis, D.K. \& Kordrostami, S. (2014). Variables reduction in data envelopment analysis, Optimatization, Vol. 63, No. 5, 2014, pp. 735-745.

[16] Golany, B.A.; Roll, Y. (1989): An application procedure for data envelopment analysis, Vol 17, No. 3 , 1989, pp. 237-250.

[17] Cooper, W.W.; Seiford, L.M.; Tone, K. (2007). Data envelopment analysis: a comprehensive text with models, applications, references and DEA-solver software, 2nd edition, Springer, ISBN 978-0-38745283-8, New York

[18] Friedman, L.; Sinuany-Stern, Z. (1998): Combining ranking scales and selecting variables in the DEA context: The case of industrial branches, Computers and Operations Research, Vol. 25, No. 9, 1998, pp. 781-791. 